\title{
Re-testing of predictive biomarkers on surgical breast cancer specimens is clinically relevant
}

\author{
Stephanie Robertson ${ }^{1,2}\left(\right.$ Caroline Rönnlund $^{1,2} \cdot$ Jana de Boniface ${ }^{3,4} \cdot$ Johan Hartman $^{1,2,5}$
}

Received: 19 December 2018 / Accepted: 21 December 2018 / Published online: 18 January 2019

(c) The Author(s) 2019

\begin{abstract}
Purpose The accuracy of predictive and prognostic biomarker assessment in breast cancer is paramount since these guide therapy decisions. The aim was to investigate the concordance of biomarkers and immunohistochemical (IHC)-based surrogate tumor subtypes between core needle biopsies (CNB) and consecutive paired breast cancer surgical resections.

Methods This retrospective study comprised two cohorts of patients with primary breast cancer diagnosed between 2016 and 2017: one treated with primary surgery $(n=526)$ and one with neoadjuvant chemotherapy (NAC) $(n=216)$. The agreement between preoperative $\mathrm{CNB}$ and paired tumor specimens regarding the assessment of biomarkers and surrogate tumor subtypes was evaluated in both cohorts.

Results In the primary surgery cohort, the concordance rates and kappa values for estrogen receptor (ER), progesterone receptor $(\mathrm{PR})$ and Ki67 were 98.6\% $(\kappa=0.917), 89.3 \%(\kappa=0.725)$ and $78.8 \%(\kappa=0.529)$, respectively. Importantly, human epidermal growth factor receptor 2 (HER2) IHC assessment showed only moderate agreement $(\kappa=0.462)$. HER2 status combining IHC and in situ hybridization was discordant in 3.6\% of cases, potentially impacting on indications for HER2-targeted therapy. The concordance rate for IHC-based surrogate tumor subtypes was only 73.2-78.3\%. Generally lower concordance rates for ER, PR and HER2 were observed in the NAC cohort. Here, HER2 status was discordant in 7.4\%.

Conclusions The agreement of HER2 and Ki67 between CNB and paired surgical specimen in primary breast cancer is insufficient. Limited agreement of surrogate tumor subtypes indicates a significant clinical value of biomarker re-testing on surgical specimens.
\end{abstract}

Keywords Breast cancer $\cdot$ Core biopsy $\cdot$ Predictive biomarker $\cdot$ Immunohistochemistry $\cdot$ Human epidermal growth factor receptor $2 \cdot \operatorname{Ki} 67$

\section{Introduction}

Breast cancer is a heterogeneous disease consisting of several distinct molecular tumor subtypes significantly differing in prognosis and therapeutic response, namely luminal

Stephanie Robertson

stephanie.robertson@ki.se

1 Department of Oncology and Pathology, CCK, Karolinska Institutet, 17176 Stockholm, Sweden

2 Department of Clinical Pathology and Cytology, Karolinska University Laboratory, Stockholm, Sweden

3 Department of Molecular Medicine and Surgery, Karolinska Institutet, Stockholm, Sweden

4 Capio St Göran's Hospital, Stockholm, Sweden

5 Stockholm South General Hospital, Stockholm, Sweden
A, luminal B, HER2-enriched and basal-like [1-4]. These intrinsic subtypes can be recapitulated using immunohistochemical (IHC) assessment of the therapy-predictive biomarkers estrogen receptor alpha (ER), progesterone receptor (PR), human epidermal growth factor receptor 2 (HER2) and Ki67 [5-8]. For confirmation of HER2 gene amplification, in situ hybridization (ISH) analysis is performed in tumors equivocal by IHC [9]. International guidelines recommend biomarker assessment to be performed on either core needle biopsies (CNB) or surgical specimens [6, 10, 11]. If IHC is performed on CNB but not on the paired surgical specimen, it could potentially lead to a faulty treatment assignment since therapy-predictive information varies between types of specimen [7, 12].

Among hormone receptor-positive/HER2-negative tumors, high proliferation (high Ki67 expression) distinguishes the more aggressive luminal B-like tumors from the 
luminal A-like and is therefore clinically important for the decision on neoadjuvant or adjuvant chemotherapy [13-15].

Approximately $15 \%$ of all primary invasive breast cancers are HER 2 positive, and the accuracy of HER 2 analysis is vital. HER2 status is instrumental to select patients with HER2-positive disease for effective targeted anti-HER2 therapy in addition to systemic chemotherapy, without which prognosis is poor [16, 17]. Insufficient concordance of HER2 status between preoperative CNB and surgical specimens can thus dramatically impact on treatment choice [12]. In the setting of neoadjuvant chemotherapy (NAC), some studies indicate insufficient concordance rates for HER2 between pre-NAC CNB and post-NAC surgical specimens, which indicates that HER2 should be re-tested after NAC $[18,19]$. The loss of HER2 positivity in the surgical specimen after NAC is associated with poor recurrence-free or disease-free survival and could potentially indicate the need for further systemic therapy [18, 20, 21]. Data on the conversion of biomarkers such as HER2 among Swedish breast cancer patients are largely lacking but an evaluation is highly relevant since laboratory methods can vary between countries and routines for re-testing differ.

Thus, the aim of this study was to investigate the value of re-testing predictive biomarkers in preoperative CNB and paired surgical specimens with a special focus on HER2 and IHC-based surrogate tumor subtypes. In addition, we aimed to investigate the clinical relevance of re-testing biomarkers in patients treated with NAC.

\section{Materials and methods}

\section{Study cohort}

The retrospective study cohort comprised patients with primary invasive breast cancer diagnosed at the Department of Clinical Pathology and Cytology, Karolinska University Laboratory, Stockholm, Sweden, during 2016 and 2017. By specific search criteria in the pathology laboratory information system, we identified 716 cases with data on biomarker assessment both on CNBs and paired surgical specimens. Two cohorts were then created: the primary surgery cohort comprised 526 cases without NAC, and the NAC cohort included 190 patients who had received NAC based on biomarker analyses from CNBs. Cases with complete pathological response (pCR) after NAC, i.e., that had no residual tumor for biomarker assessment left after NAC, or patients treated with neoadjuvant endocrine therapy alone, were not included.

The clinicopathological data retrieved from routine pathology reports comprised tumor characteristics (histological subtype, tumor size, Nottingham Histological Grade), axillary lymph node status, IHC biomarker status for ER, PR, Ki67 and HER2, ISH status for HER2 and tumor response to NAC. Details on type of neoadjuvant therapy were retrieved from the medical record system. The data collection was performed between January 6 and March 17, 2018.

At the accredited laboratory of the Department of Clinical Pathology and Cytology, Karolinska University Laboratory, Stockholm, Sweden, the routine immunohistochemistry staining protocol for breast cancer biomarkers utilized monoclonal rabbit anti-ER (clone SP1), anti-PR (clone 1E2), anti-Ki67 (clone 30-9) and anti-HER-2/neu (clone 4B5) antibodies and had been performed according to the manufacturer's instructions (BenchMark ULTRA Staining Module, Ventana Medical Systems, Arizona, USA). For equivocal HER2 protein expression results by IHC, further analysis with ISH had been performed [16]. Routine biomarker assessment and scoring had been performed according to national guidelines. The reported overall HER2 status was based on combined results from IHC protein expression and gene amplification and included ISH HER2/chromosome 17 probe $(\mathrm{C} 17)$ ratio and average number of HER2 copy numbers.

\section{Cutoffs for biomarker concordance analysis}

Biomarker values were retrospectively collected, and no new assessments were performed in this study. For biomarker concordance analysis, we applied a cutoff value of $\geq 10 \%$ for ER positivity, $\geq 10 \%$ for PR positivity and $\geq 20 \%$ for high proliferation as measured by Ki67 [10, 22]. Negative HER 2 protein expression was defined as score 0 or $1+$, and positive as $3+$. Equivocal tumors, scored $2+$, had in most cases been subjected to additional ISH. After ISH assessment, a HER 2 copy/C17 control ratio $>2.0$ or an average HER 2 copy number $>4.0$ signals/cell were classified as HER2 positivity. Negative HER2 status was defined as IHC score 0 or $1+$, or ISH HER $2 / C 17$ ratio $<2.0$ and HER 2 copy number $<4.0$ signals/cell [16].

\section{IHC-based surrogate tumor subtype classification}

For subtype classification, we compared two different surrogate definitions: those of the St. Gallen consensus meeting in 2013 and those of the current Swedish guidelines which are based on published work by Maisonneuve et al., see Table 1 $[10,15,22,23]$. For the latter, we applied Ki67 cutoffs as follows: $0-14 \%=$ low, $15-22 \%=$ intermediate and $23-100 \%$ $=$ high. For ER-positive, HER2-negative tumors with intermediate proliferation, PR levels of $\geq 20 \%$ or $<20 \%$ divide this group into luminal A-like or luminal B-like, respectively $[10,15]$. 
Table 1 Immunohistochemicalbased surrogate tumor subtype definitions for breast cancer

\begin{tabular}{|c|c|}
\hline Intrinsic surrogate tumor subtype & Clinicopathological surrogate definition \\
\hline \multicolumn{2}{|l|}{ Swedish surrogate tumor subtype } \\
\hline Luminal A-like & $\begin{array}{l}\text { ER positive }(\geq 10 \%) \text { and HER2 negative } \\
\text { and } \\
\text { Low Ki67 }(<14 \%)^{\mathrm{a}} \text { or } \\
\text { Intermediate Ki67 (15-22\%) and PR } \geq 20 \%\end{array}$ \\
\hline Luminal B-like & $\begin{array}{l}\text { ER positive }(\geq 10 \%) \text { and HER2 negative } \\
\text { and } \\
\text { High Ki67 (> 23\%) or } \\
\text { Intermediate Ki67 (15-22\%) and PR }<20 \%\end{array}$ \\
\hline HER2-positive/luminal & $\begin{array}{l}\text { ER positive }(\geq 10 \%) \text { and HER } 2 \text { positive } \\
\text { and } \\
\text { Any Ki67/PR }\end{array}$ \\
\hline HER2-positive/non-luminal & HER2 positive and ER negative $(<10 \%)$ and PR negative $(<10 \%)$ \\
\hline Triple negative & ER negative $(<10 \%)$ and PR negative $(<10 \%)$ and HER2 negative \\
\hline \multicolumn{2}{|l|}{ St. Gallen surrogate tumor subtype } \\
\hline Luminal A-like & $\begin{array}{l}\text { ER positive }(\geq 1 \%) \text { and } P R \text { positive }(\geq 20 \%[23]) \\
\text { and } \\
\text { HER2 negative } \\
\text { and } \\
\text { Ki67 low ( }<20 \% \text {; panel consensus) }\end{array}$ \\
\hline Luminal B-like (HER2 negative) & $\begin{array}{l}\text { ER positive }(\geq 1 \%) \\
\text { HER2 negative } \\
\text { and at least one of } \\
\text { Ki67 high }(\geq 20 \% \text {; panel consensus) } \\
\text { PR negative or low }(<20 \%[23])\end{array}$ \\
\hline Luminal B-like (HER2 positive) & $\begin{array}{l}\text { ER positive }(\geq 1 \%) \\
\text { HER } 2 \text { over-expressed or amplified } \\
\text { any Ki67/PR }\end{array}$ \\
\hline HER2 positive (non-luminal) & $\begin{array}{l}\text { HER2 over-expressed or amplified } \\
\text { ER and PR absent }(<1 \%)\end{array}$ \\
\hline Triple negative (ductal) & $\begin{array}{l}\text { ER and PR absent }(<1 \%) \\
\text { HER2 negative }\end{array}$ \\
\hline
\end{tabular}

$E R$ estrogen receptor; $P R$ progesterone receptor; HER2 human epidermal growth factor receptor 2

${ }^{\mathrm{a}} \mathrm{Ki} 67$ cutoffs are laboratory-specific and provided nationally each year

\section{Statistical analysis}

The Kolmogorov-Smirnov test was used to test for normality, and accordingly only nonparametric tests were applied. Comparison of proportions with categorical outcome was performed with the Chi-square test and Fisher's exact test, respectively. Nonparametric significance tests for two dependent variables were as follows: Fisher's exact test for paired samples with two categories and the Marginal Homogeneity test for paired variables with more than two categories (HER2 IHC score and IHC-based subtype). The related-samples Wilcoxon signed rank test was applied for continuous outcome comparisons. Cohen's $\kappa$ statistics are presented as a measure of agreement between the biomarker assessments. We applied the Landis and
Koch 1977 agreement grades for kappa values: 0.21-0.4 as fair, $0.41-0.6$ as moderate, $0.61-0.8$ as substantial, and $0.81-1$ as almost perfect agreement. In analogy to 'numbers needed to treat', we defined 'numbers needed to reclassify' (NNRC) as 1/risk of re-classification. The risk of re-classification was calculated as number of cases that changed from positive to negative status or from high to low proliferation, divided by the total number of cases. All statistical tests were two-sided, and significance was considered at $p<0.05$. All statistical analyses were performed using SPSS version 24.0 (IBM Corp., Armonk, USA). Sankey diagrams illustrating changes in subtype classifications were computed in JSFiddle V.0.5a2 (http:// jsfiddle.net). 


\section{Results}

\section{Tumor characteristics and IHC biomarker results}

The primary surgery cohort consisted of 526 cases, while the NAC cohort included 190 cases. Tumor and patient characteristics are presented in Table 2. Probably due to the exclusion of pCR cases, axillary lymph node metastases were more frequent in the NAC than in the primary surgery cohort.
In the primary surgery cohort, there were significant differences in median ER, PR and Ki67\% between CNB and surgical specimen: ER 99\% versus $95 \%(p=0.019)$, PR $70 \%$ versus $60 \%(p=0.023)$, Ki67 24\% versus $28 \%(p<0.001)$, respectively. Overall, $89.2 \%$ of the tumors were ER positive and $72.6 \%$ PR positive on the surgical specimen. As expected, these figures were somewhat lower in the NAC cohort based on pre-NAC CNB, with $75.8 \%(p<0.001)$ and $63.2 \%(p=0.044)$, respectively. In agreement with this, $67.5 \%$ of tumors in the primary surgery cohort had a
Table 2 Tumor characteristics for both study cohorts

\begin{tabular}{|c|c|c|c|}
\hline & $\begin{array}{l}\text { Primary surgery cohort } \\
(n=526)\end{array}$ & \multicolumn{2}{|c|}{$\begin{array}{l}\text { Neoadjuvant chemother- } \\
\text { apy cohort }(n=190)\end{array}$} \\
\hline Diagnostic period & 2016-2017 & \multicolumn{2}{|c|}{ 2016-2017 } \\
\hline Age at diagnosis, median (years (range)) & $65(26-97)$ & \multicolumn{2}{|c|}{$51(29-85)$} \\
\hline Histopathological tumor size, median (mm & $20(1-150)$ & \multicolumn{2}{|c|}{$21(1-180)$} \\
\hline & $n(\%)$ & & $n(\%)$ \\
\hline \multicolumn{4}{|l|}{ Pathological T-stage (TNM 7) ${ }^{\mathrm{a}}$} \\
\hline pT1 & $264(50.2)$ & ypT1 & $91(47.9)$ \\
\hline $\mathrm{pT} 2$ & $222(42.2)$ & ypT2 & $72(37.9)$ \\
\hline pT3 & $39(7.4)$ & ypT3 & $25(13.2)$ \\
\hline Missing & $1(0.2)$ & Missing & $2(1.1)$ \\
\hline Multifocality & $103(19.6)$ & & $36(18.9)$ \\
\hline \multicolumn{4}{|l|}{ Pathological N-stage (TNM 7) ${ }^{\mathrm{a}}$} \\
\hline pN0 & $315(59.9)$ & ypN0 & $65(34.2)$ \\
\hline $\mathrm{pN} 1$ & $135(25.7)$ & ypN1 & $86(45.3)$ \\
\hline $\mathrm{pN} 2$ & $44(8.4)$ & ypN2 & $24(12.6)$ \\
\hline $\mathrm{pN} 3$ & $21(4.0)$ & ypN3 & $12(6.3)$ \\
\hline Missing & $11(2.1)$ & Missing & $3(1.6)$ \\
\hline \multicolumn{4}{|l|}{ Pathological response to neoadjuvant treatment } \\
\hline No response & - & & $21(11.1)$ \\
\hline Partial response & - & & $146(76.8)$ \\
\hline Response not reported & - & & $23(12.1)$ \\
\hline Histologic type & Surgical specimen & & CNB \\
\hline Invasive carcinoma NST/ductal & $316(60.1)$ & & $130(68.4)$ \\
\hline Invasive lobular carcinoma & $99(18.8)$ & & $18(9.5)$ \\
\hline Mucinous carcinoma & $15(2.9)$ & & $6(3.2)$ \\
\hline Tubular carcinoma & $10(1.9)$ & & $0(0.0)$ \\
\hline Papillary carcinoma & $4(0.8)$ & & $1(0.5)$ \\
\hline Mixed subtype & $5(1.0)$ & & $0(0.0)$ \\
\hline Unclassified & $77(14.6)$ & & $35(18.4)$ \\
\hline Nottingham histological grade & Surgical specimen & & $\mathrm{CNB}$ \\
\hline Grade 1 & $65(12.4)$ & & $7(3.7)$ \\
\hline Grade 2 & $269(51.1)$ & & $96(50.5)$ \\
\hline Grade 3 & 189 (35.9) & & $65(34.2)$ \\
\hline Unclassified & $3(0.6)$ & & $22(11.6)$ \\
\hline
\end{tabular}

$C N B$ core needle biopsy, NST nonspecial type

${ }^{\text {a } P a t h o l o g i c a l ~} \mathrm{~T}$ stage for invasive tumor and pathological $\mathrm{N}$ stage for regional lymph nodes including sentinel lymph nodes 
high proliferation (Ki67) as compared to $88.4 \%$ in the NAC cohort (cutoff $\geq 20 \% ; p<0.001$ ).

Combining HER2 IHC and ISH results into HER2 status, HER 2 positivity was $9.5 \%$ on CNB and $11.4 \%$ on surgical specimens without NAC. In the NAC cohort, HER2 positivity was $17.4 \%$ and $12.1 \%$, respectively.

\section{Concordance of ER, PR and Ki67}

In the primary surgery cohort, ER status showed an almost perfect and PR status a substantial agreement (Table 3). For ER, 73 tumors needed to be assessed on CNB in order for one case to be re-classified on the surgical specimen (NNRC $=73$ ), while for PR, NNRC was only 10 . Only moderate agreement was observed for Ki67 using a cutoff of $\geq 20 \%$ for high proliferation (Table 3 ). Here, only 5 tumors needed to be assessed on CNB before one was re-classified on the surgical specimen $(\mathrm{NNRC}=5)$. Similar results were seen for ER and PR in the NAC cohort (Table 4). Here, NAC effects showed a decreased proliferative index as measured by Ki67, resulting in an only slight degree of agreement.

\section{Agreement of HER2 status}

The agreement of HER2 status between CNB and the surgical specimen could be analyzed in 502 tumors from the primary surgery cohort. HER2 IHC-negative cases were slightly more common in CNB than in the surgical specimen. Concordance of HER2 IHC was only $75.4 \%$, implying a moderate agreement, which clearly improved when combining IHC scores and the subsequent ISH analysis into a negative or positive HER2 status (Table 5). Importantly, 18 tumors (3.6\%) had a discordant HER2 status. Out of these, 13 tumors were assessed as HER2 negative on CNB but were positive in the resected specimen. A further 5 tumors were HER2 positive on CNB but turned out negative in the resected specimen. For HER2 status, 28 tumors needed to be assessed on CNB in order for one to be re-classified based on the surgical specimen $(\mathrm{NNRC}=28)($ Table 5).
Table 3 Analysis of agreement between core needle biopsy and surgical specimen for ER, PR and Ki67 in cases treated with surgery as primary therapy
Table 4 Analysis of agreement between core needle biopsy and surgical specimen for ER, PR and Ki67 in cases treated with neoadjuvant chemotherapy

\begin{tabular}{|c|c|c|c|c|c|c|}
\hline & & \multicolumn{2}{|c|}{ Surgical specimen } & \multirow{2}{*}{$\begin{array}{l}\text { Concordance } \\
\text { rate }(\%)\end{array}$} & \multirow[t]{2}{*}{$\kappa$-value } & \multirow[t]{2}{*}{ NNRC } \\
\hline & & ER- & $\mathrm{ER}+$ & & & \\
\hline & ER- & 43 & 3 & 98.6 & 0.917 & 73 \\
\hline & ER+ & 4 & 461 & & & \\
\hline $\mathrm{C}$ & & PR- & $\mathrm{PR}+$ & & & \\
\hline $\mathrm{N}$ & PR- & 104 & 31 & 89.3 & 0.725 & 10 \\
\hline \multirow[t]{4}{*}{ B } & $\mathrm{PR}+$ & 22 & 340 & & & \\
\hline & & Ki67 low & Ki67 high & & & \\
\hline & Ki67 low & 122 & 66 & 78.8 & 0.529 & 5 \\
\hline & Ki67 high & 44 & 286 & & & \\
\hline
\end{tabular}

Positive ER and PR status defined with a $\geq 10 \%$ cut off and high Ki67 was defined as $\geq 20 \%$

$C N B$ core needle biopsy, ER estrogen receptor, $P R$ progesterone receptor, $N N R C$ numbers needed to reclassify $(=1 /(\mathrm{n}$ reclassified/total $\mathrm{n}))$

\begin{tabular}{|c|c|c|c|c|c|c|}
\hline & & \multicolumn{2}{|c|}{ Surgical specimen } & \multirow[t]{2}{*}{ Concordance rate $(\%)$} & \multirow[t]{2}{*}{$\kappa$-value } & \multirow[t]{2}{*}{ NNRC } \\
\hline & & ER- & $\mathrm{ER}+$ & & & \\
\hline & ER- & 36 & 4 & 96.2 & 0.887 & 27 \\
\hline & $\mathrm{ER}+$ & 3 & 141 & & & \\
\hline $\mathrm{C}$ & & PR- & $\mathrm{PR}+$ & & & \\
\hline $\mathrm{N}$ & PR- & 56 & 6 & 73.9 & 0.490 & 4 \\
\hline \multirow[t]{4}{*}{ B } & $\mathrm{PR}+$ & 41 & 77 & & & \\
\hline & & Ki67 low & Ki67 high & & & \\
\hline & Ki67 low & 18 & 2 & 40.9 & 0.075 & 2 \\
\hline & Ki67 high & 108 & 58 & & & \\
\hline
\end{tabular}

Positive ER and PR status defined with a $\geq 10 \%$ cut off and high Ki67 was defined as $\geq 20 \%$

$C N B$ core needle biopsy, $E R$ estrogen receptor, $P R$ progesterone receptor, $N N R C$ numbers needed to reclassify $(=1 /(\mathrm{n}$ reclassified/total $\mathrm{n}))$ 
Among the discordant cases in the primary surgery cohort, 6 equivocal cases (IHC 2+) with identical IHC score between CNB and surgical specimen, showed HER2 amplification only on the surgical specimen. This underlines the value of re-testing HER2 even for equivocal cases with a negative ISH on CNB, as HER2 status guides clinical treatment decisions.

In the NAC cohort, the agreement of HER2 status between pre-NAC CNB and post-NAC histopathology was substantial, but only moderate for HER2 IHC assignment (Table 6). Of clinical interest, 10 tumors were HER2 positive on CNB but lost either HER2 expression and/ or gene amplification after NAC. Conversely, one tumor assessed as negative on CNB had a positive HER2 status after NAC.

\section{Concordance for IHC-based surrogate tumor subtypes}

We performed IHC-based surrogate subtype classification on CNB and surgical specimens, both according to the St.
Gallen International Expert Consensus from 2013 and the current Swedish guidelines [8, 10]. In the primary surgery cohort, 470 tumors had complete data for comparison of subtype classification according to St. Gallen and Swedish guideline subtypes. The concordance rates applying St. Gallen subtype and the Swedish guideline definitions were $78.3 \%(\kappa=0.631)$ and $73.2 \%(\kappa=0.589)$, respectively. Using Swedish guideline definitions, 76 out of 202 (37.6\%) luminal A-like tumors diagnosed on preoperative CNB were re-classified into luminal B-like on the paired surgical specimen. Similar results were observed with the St. Gallen subtype definitions (48 out of 127, 37.8\%) (Fig. 1). The overall concordance rate for luminal HER2- tumors only in the primary surgery cohort was $80.3 \%$ and $72.8 \%$ with St. Gallen and Swedish definitions, respectively.

Among cases in the NAC cohort, the corresponding concordance rate for all subtypes with St. Gallen definitions was $63.8 \%(\kappa=0.460$, total $n=160)$ and $53.1 \%$ with the Swedish guideline definitions $(\kappa=0.408$, total $n=162)$. (Fig. 2$)$.

Table 5 Analysis of agreement between core needle biopsy and surgical specimen for HER2 in cases treated with surgery as primary therapy

\begin{tabular}{|c|c|c|c|c|c|c|c|}
\hline & & \multicolumn{3}{|c|}{ Surgical specimen } & \multirow[t]{2}{*}{ Concordance rate $(\%)$} & \multirow[t]{2}{*}{$\kappa$-value } & \multirow[t]{2}{*}{ NNRC } \\
\hline & & HER2 IHC neg & HER2 IHC equivocal & HER2 IHC pos & & & \\
\hline & HER2 IHC neg ${ }^{a}$ & 299 & 70 & 3 & & & \\
\hline $\mathrm{C}$ & HER2 IHC equivocal & 41 & 51 & 7 & 75.4 & 0.462 & - \\
\hline $\mathrm{N}$ & HER2 IHC pos & 1 & 3 & 34 & & & \\
\hline \multirow[t]{3}{*}{ B } & & HER2 neg & HER2 pos & & & & \\
\hline & HER2 neg ${ }^{b}$ & 439 & 13 & & 96.4 & 0.813 & 28 \\
\hline & HER2 pos & 5 & 45 & & & & \\
\hline
\end{tabular}

$C N B$ core needle biopsy, HER2 human epidermal growth factor receptor 2, $N N R C$ numbers needed to re-classify $(=1 /(\mathrm{n}$ reclassified/total $\mathrm{n}))$ ${ }^{a}$ HER2 IHC score: $0-1+=$ negative, $2+=$ equivocal, $3+=$ positive

${ }^{\mathrm{b}} \mathrm{HER} 2$ status based on IHC score and results from in situ hybridization analysis

Table 6 Analysis of agreement between core needle biopsy and surgical specimen for HER2 in cases treated with neoadjuvant chemotherapy

\begin{tabular}{|c|c|c|c|c|c|c|c|}
\hline & & \multicolumn{3}{|c|}{ Surgical specimen } & \multirow{2}{*}{$\begin{array}{l}\text { Concordance } \\
\text { rate }(\%)\end{array}$} & \multirow[t]{2}{*}{$\kappa$-value } & \multirow[t]{2}{*}{ NNRC } \\
\hline & & HER2 IHC neg & $\begin{array}{l}\text { HER2 IHC } \\
\text { equivocal }\end{array}$ & HER2 IHC pos & & & \\
\hline & HER2 IHC ${ }^{a}$ neg & 103 & 13 & 1 & & & \\
\hline $\mathrm{C}$ & HER2 IHC equivocal & 22 & 29 & 1 & 76.7 & 0.539 & - \\
\hline $\mathrm{N}$ & HER2 IHC pos & 3 & 4 & 13 & & & \\
\hline \multirow[t]{3}{*}{ B } & & HER2 neg & HER2 pos & & & & \\
\hline & HER $2^{b}$ neg & 144 & 1 & & 93.8 & 0.757 & 16 \\
\hline & HER2 pos & 10 & 21 & & & & \\
\hline
\end{tabular}

$C N B$ core needle biopsy, $H E R 2$ human epidermal growth factor receptor $2, N N R C$ numbers needed to re-classify $(=1 /(\mathrm{n}$ reclassified/total $\mathrm{n}))$

${ }^{a}$ HER2 IHC score: $0-1+=$ negative, $2+=$ equivocal, $3+=$ positive

${ }^{\mathrm{b}} \mathrm{HER} 2$ status based on IHC score and results from in situ hybridization analysis 
A

Surrogate tumor subtype re-classification

Luminal A-like CNB $(n=127)$

Luminal A-like SS ( $n=104)$

Luminal B-like (HER2-) CNB ( $n=269)$

Luminal B-like (HER2-) SS ( $\mathrm{n}=280)$

Luminal B-like (HER2+) CNB $(n=39)$

Luminal B-like (HER2+) SS ( $n=42)$

HER2+ (non-luminal) CNB ( $n=10)$

HER2+ (non-luminal) SS ( $n=14)$

Triple negative CNB $(n=25)$

Triple negative SS $(n=30)$

B

Luminal A-like CNB $(n=202)$

Luminal A-like SS $(n=149)$

Luminal B-like SS $(n=233)$

Luminal B-like CNB ( $n=190)$

HER2+/luminal CNB ( $n=34)$

HER2+/luminal SS ( $n=41)$

HER2+/non-luminal CNB ( $n=15)$

HER2+/non-luminal SS ( $n=15)$

Triple negative CNB $(n=29)$

Triple negative SS $(n=32)$

Fig. 1 Sankey diagrams for immunohistochemical (IHC)-based surrogate tumor subtype re-classification in core needle biopsy (CNB) versus paired surgical specimen (SS) in the primary surgery cohort.

\section{Discussion}

Core needle biopsy is a well-established and reliable diagnostic method for histopathological diagnosis of breast carcinoma and provides sufficient material for IHC assessment of biomarkers [24, 25]. In addition, the accuracy of biomarkers including ER, PR, HER2 and Ki67 in pre-therapeutic biopsies of early breast cancer is of great importance for therapy decisions and especially for the selection of candidates for NAC. Adjuvant therapy planning may be based on either CNB or surgical specimen, although there are inconsistent results regarding the concordance of specific biomarkers [26-29].

In the present study, we investigated the agreement of biomarkers between CNB and surgical specimen in patients
Surrogate tumor subtype re-classification according to St. Gallen definitions (a) and Swedish guideline definitions (b)

who underwent surgery as primary treatment or received neoadjuvant chemotherapy. The higher concordance rate for ER than PR in this study is in line with previous findings $[27,30]$. A previous study by Chen et al. reported approximately $14 \%$ re-classification rate from luminal A-like on CNB to luminal B-like on surgical specimens among hormone receptor (HR)+/HER2 - tumors, and suggested Ki67 to be repeated on surgical specimen [31]. In the present investigation, the re-classification rate was substantially higher. Since luminal B-like tumors are more likely to receive chemotherapy and to be subject to NAC, this could have significant clinical implications. There is a trend toward an underestimation of the proportion of luminal B-like tumors on CNB. Even though Ki67 is an important factor in distinguishing luminal-like disease, it is prone to 


\section{A Surrogate tumor subtype re-classification}

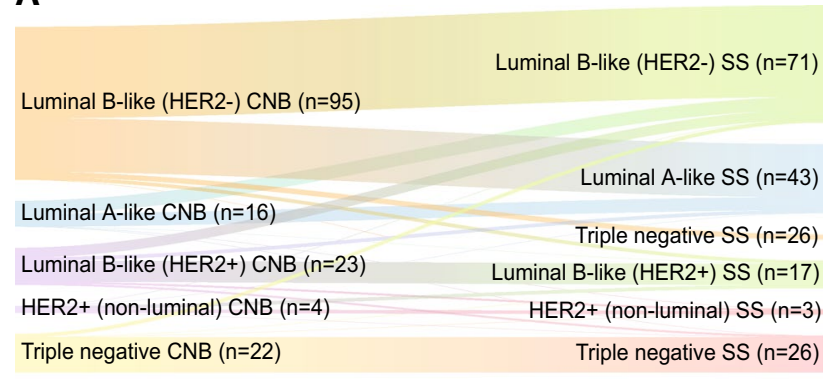

\section{B}

Luminal B-like CNB $(n=76)$

Luminal A-like SS ( $n=88$ )

Luminal A-like CNB $(n=28)$

HER2+/luminal CNB ( $n=21)$

Luminal B-like SS ( $n=21)$

HER2+/non-luminal CNB $(n=6)$

HER2+/luminal SS $(n=16)$

Triple negative CNB $(n=31)$

Triple negative SS $(n=33)$

Fig. 2 Sankey diagrams for immunohistochemical (IHC)-based surrogate tumor subtype re-classification in core needle biopsy (CNB) versus paired surgical specimen (SS) in the NAC cohort according to definitions by St. Gallen (a) and Swedish guidelines (b)

inter- and intraobserver variability and has a heterogeneous expression [32,33]. You et al. reported concordance rates as high as $83.5 \%(\kappa=0.647)$ for Ki67, probably because Ki67 index had been assessed using $10 \%$ intervals instead of a continuous percentage (20\% cutoff for high proliferation). Furthermore, they reported a HER2 IHC concordance of $84.8 \%(\kappa=0.684)$ [34].

We show a lower overall concordance for IHC-based surrogate tumor subtypes using St. Gallen definitions than previous studies [30, 31]. Meattini et al. showed a significantly higher concordance rate between $\mathrm{CNBs}$ and surgical specimens than our study: $87.1 \%(\kappa=0.78)$. Among $\mathrm{HR}+$ l HER2-tumors, however, the agreement was lower [30].

Even though the concordance rate for HER2 status including ISH was high, already a small discordance rate may have serious implications for patients not receiving lifesaving HER2-targeted therapy. In a large study by Arnedos et al., the reported HER2 concordance rate was as high as 98.8\% and showed low levels of amplification in discordant HER2 cases [27]. A high concordance for HER2 (98.3\%) was also reported by Lorgis et al., although their cohort comprised a low number of HER2-positive tumors (5.7\%), which appears to be insufficient for further conclusions [28]. In a large study with pooled data, Dekker et al. reported a $97.8 \%$ concordance for HER2 status [35]. Slightly lower HER2 status concordance rates have also been reported [30,35]. In the present study, HER 2 assessment between 2016 and 2017

followed recent ASCO/CAP guidelines [16]. In the updated guidelines, histopathologic features are suggested for consideration in HER2 discordant cases [9]. Caution should be taken when assessing HER2 in biopsy specimens as they may be affected by artefacts, which can potentially lead to inaccurate HER2 assignment [36, 37].

Breast cancer is a heterogeneous disease exhibiting phenotypic and genetic intra-tumor heterogeneity [38-40]. Studying different areas of the same tumor, biomarker protein (IHC) expression shows larger intra-tumor heterogeneity than observed mRNA levels, especially for Ki67 and PR [41]. Furthermore, significant discordance of HER2 between CNB and surgical resection specimen has been seen among heterogeneous tumors [12]. Sampling different tumor regions as with CNBs may therefore affect biomarker agreement as seen in the present study. Low concordance in biomarker status has also been identified between aspiration cytology and histology-based assessments as a sign of sampling error [42, 43].

Changes in biomarker status after NAC hold important information about tumor biology. Upon assessment, loss of HER2 expression or gene amplification was observed in 10 tumors and conversely, one tumor showed HER2 gene amplification after NAC. Hormone receptor and HER2 status may change during tumor progression [44]. Intrinsic molecular subtypes have been investigated in paired primary and metastatic samples and are generally maintained during metastatic progression. Results from Cevaljo et al. showed, however, that $55 \%$ of initially luminal A tumors converted to luminal B and HER2-enriched [45]. The conversion of luminal A primary tumors to non-luminal A metastatic disease has been demonstrated repeatedly [46]. Interestingly, Cevaljo et al. also found an increase in fibroblast growth factor receptor 4 (FGFR4) gene expression but not ERBB2 expression in HER2-enriched metastasis that had converted from luminal primary tumors [45]. Overexpression of FGFR4 is a characteristic feature of the HER2-enriched subtype.

There are certain limitations to be considered. First, the study had a retrospective design, and results cannot be generalized. Second, a number of patients were diagnosed at other laboratories and referred to the hospital for surgery. CNBs diagnoses were confirmed on surgical resections, but biomarkers and in situ hybridization results were not always re-assessed, and thus not included in the study. Third, patients subjected to CNB instead on fine needle aspiration cytology before surgical treatment are a selected group as they tend to have larger or node-positive tumors prone to receive NAC. It could also be patients with inoperable disease or those not fit for surgery. In addition, patients with complete pathological response to NAC were not included in this study as no remaining tumor tissue could be assessed. 
To conclude, the agreement of HER2 and Ki67 between $\mathrm{CNB}$ and paired surgical specimen in primary breast cancer is insufficient. An only moderate agreement of surrogate tumor subtypes indicates the clinical value of biomarker re-testing on surgical specimens, and re-testing of at least HER 2 and Ki67 should be considered to optimize tailored adjuvant therapy especially for patients treated with NAC.

Funding This work was supported by grants from the Swedish Society for Medical Research (SSMF), the Swedish Cancer Society, the Stockholm Cancer Society, the King Gustaf V Jubilee Fund, Karolinska Institutet, the Stockholm County Council Research Strategy Committee and the Swedish Breast Cancer Association (BRO).

\section{Compliance with ethical standards}

Conflict of interest JH is scientific advisor of Visiopharm AG and has obtained advisory board fees from AstraZeneca and Novartis, honoraria and speakers bureau from Roche $\mathrm{AB}$. The other authors declare no conflict of interest.

Ethical approval All procedures performed in studies involving human participants were in accordance with the ethical standards of the institutional research committee (Research Ethics Committee at Karolinska Institutet, Stockholm, Sweden) and with the 1964 Helsinki Declaration and its later amendments or comparable ethical standards.

Informed consent The study was based on retrospective clinical data, and no additional patient consent was required in accordance to ethical approval. However, prior to surgery, all patients have approved storage of material in the Stockholm Medical Biobank for clinical and research purposes.

Open Access This article is distributed under the terms of the Creative Commons Attribution 4.0 International License (http://creativeco mmons.org/licenses/by/4.0/), which permits unrestricted use, distribution, and reproduction in any medium, provided you give appropriate credit to the original author(s) and the source, provide a link to the Creative Commons license, and indicate if changes were made.

\section{References}

1. Sorlie T, Perou CM, Tibshirani R, Aas T, Geisler S, Johnsen H, Hastie T, Eisen MB, van de Rijn M, Jeffrey SS, Thorsen T, Quist $\mathrm{H}$, Matese JC, Brown PO, Botstein D, Lonning PE, BorresenDale AL (2001) Gene expression patterns of breast carcinomas distinguish tumor subclasses with clinical implications. Proc Natl Acad Sci USA 98(19):10869-10874. https://doi.org/10.1073/ pnas. 191367098

2. Perou CM, Sorlie T, Eisen MB, van de Rijn M, Jeffrey SS, Rees CA, Pollack JR, Ross DT, Johnsen H, Akslen LA, Fluge O, Pergamenschikov A, Williams C, Zhu SX, Lonning PE, BorresenDale AL, Brown PO, Botstein D (2000) Molecular portraits of human breast tumours. Nature 406(6797):747-752. https://doi. org/10.1038/35021093

3. Parker JS, Mullins M, Cheang MC, Leung S, Voduc D, Vickery T, Davies S, Fauron C, He X, Hu Z, Quackenbush JF, Stijleman IJ, Palazzo J, Marron JS, Nobel AB, Mardis E, Nielsen TO, Ellis MJ, Perou CM, Bernard PS (2009) Supervised risk predictor of breast cancer based on intrinsic subtypes. J Clin Oncol 27(8):1160-1167. https://doi.org/10.1200/jco.2008.18.1370

4. Sorlie T, Tibshirani R, Parker J, Hastie T, Marron JS, Nobel A, Deng S, Johnsen H, Pesich R, Geisler S, Demeter J, Perou CM, Lonning PE, Brown PO, Borresen-Dale AL, Botstein D (2003) Repeated observation of breast tumor subtypes in independent gene expression data sets. Proc Natl Acad Sci USA 100(14):84188423. https://doi.org/10.1073/pnas.0932692100

5. Guiu S, Michiels S, Andre F, Cortes J, Denkert C, Di Leo A, Hennessy BT, Sorlie T, Sotiriou C, Turner N, Van de Vijver M, Viale G, Loi S, Reis-Filho JS (2012) Molecular subclasses of breast cancer: how do we define them? The IMPAKT 2012 working group statement. Ann Oncol 23(12):2997-3006. https://doi. org/10.1093/annonc/mds586

6. Coates AS, Winer EP, Goldhirsch A, Gelber RD, Gnant M, Piccart-Gebhart M, Thurlimann B, Senn HJ, Panel M (2015) Tailoring therapies-improving the management of early breast cancer: St Gallen international expert consensus on the primary therapy of early breast cancer 2015. Ann Oncol 26(8):1533-1546. https ://doi.org/10.1093/annonc/mdv221

7. Goldhirsch A, Wood WC, Coates AS, Gelber RD, Thurlimann B, Senn HJ (2011) Strategies for subtypes-dealing with the diversity of breast cancer: highlights of the St. Gallen international expert consensus on the primary therapy of early breast cancer 2011. Ann Oncol 22(8):1736-1747. https://doi.org/10.1093/annon c/mdr304

8. Goldhirsch A, Winer EP, Coates AS, Gelber RD, Piccart-Gebhart M, Thurlimann B, Senn HJ (2013) Personalizing the treatment of women with early breast cancer: highlights of the St Gallen international expert consensus on the primary therapy of early breast cancer 2013. Ann Oncol 24(9):2206-2223. https://doi. org/10.1093/annonc/mdt303

9. Wolff AC, Hammond MEH, Allison KH, Harvey BE, Mangu PB, Bartlett JMS, Bilous M, Ellis IO, Fitzgibbons P, Hanna W, Jenkins RB, Press MF, Spears PA, Vance GH, Viale G, McShane LM, Dowsett M (2018) Human epidermal growth factor receptor 2 testing in breast cancer: American Society of Clinical Oncology/College of American Pathologists clinical practice guideline focused update. J Clin Oncol. https://doi.org/10.1200/jco.2018.77.8738

10. Regional cancer center Stockholm Gotland (2018) National care program Breast cancer. Regional cancer centers. https://www. cancercentrum.se/stockholm-gotland/cancerdiagnoser/brost/vardp rogram/. Accessed 17 Dec 2018

11. Grabau D (2014) Quality- and standardization committee (KVAST). Quality- and standadization document for breast tumors. Swedish Pathological Society/Swedish Society of Clinical Cytology, Alingsås

12. Greer LT, Rosman M, Mylander WC, Hooke J, Kovatich A, Sawyer K, Buras RR, Shriver CD, Tafra L (2013) Does breast tumor heterogeneity necessitate further immunohistochemical staining on surgical specimens? J Am Coll Surg 216(2):239-251. https:// doi.org/10.1016/j.jamcollsurg.2012.09.007

13. Urruticoechea A, Smith IE, Dowsett M (2005) Proliferation marker Ki-67 in early breast cancer. J Clin Oncol 23(28):72127220. https://doi.org/10.1200/jco.2005.07.501

14. Criscitiello C, Disalvatore D, De Laurentiis M, Gelao L, Fumagalli L, Locatelli M, Bagnardi V, Rotmensz N, Esposito A, Minchella I, De Placido S, Santangelo M, Viale G, Goldhirsch A, Curigliano $\mathrm{G}$ (2014) High Ki-67 score is indicative of a greater benefit from adjuvant chemotherapy when added to endocrine therapy in luminal B HER2 negative and node-positive breast cancer. Breast 23(1):69-75. https://doi.org/10.1016/j.breast.2013.11.007

15. Maisonneuve P, Disalvatore D, Rotmensz N, Curigliano G, Colleoni M, Dellapasqua S, Pruneri G, Mastropasqua MG, Luini A, Bassi F, Pagani G, Viale G, Goldhirsch A (2014) Proposed new clinicopathological surrogate definitions of luminal A and luminal 
B (HER2-negative) intrinsic breast cancer subtypes. Breast Cancer Res 16(3):R65-R65. https://doi.org/10.1186/bcr3679

16. Wolff AC, Hammond ME, Hicks DG, Dowsett M, McShane LM, Allison KH, Allred DC, Bartlett JM, Bilous M, Fitzgibbons P, Hanna W, Jenkins RB, Mangu PB, Paik S, Perez EA, Press MF, Spears PA, Vance GH, Viale G, Hayes DF (2013) Recommendations for human epidermal growth factor receptor 2 testing in breast cancer: American Society of Clinical Oncology/ College of American Pathologists clinical practice guideline update. J Clin Oncol 31(31):3997-4013. https://doi.org/10.1200/ jco.2013.50.9984

17. Slamon DJ, Clark GM, Wong SG, Levin WJ, Ullrich A, McGuire WL (1987) Human breast cancer: correlation of relapse and survival with amplification of the HER-2/neu oncogene. Science 235(4785):177-182

18. Mittendorf EA, Wu Y, Scaltriti M, Meric-Bernstam F, Hunt KK, Dawood S, Esteva FJ, Buzdar AU, Chen H, Eksambi S, Hortobagyi GN, Baselga J, Gonzalez-Angulo AM (2009) Loss of HER2 amplification following trastuzumab-based neoadjuvant systemic therapy and survival outcomes. Clin Cancer Res 15(23):73817388. https://doi.org/10.1158/1078-0432.Ccr-09-1735

19. van de Ven S, Smit VT, Dekker TJ, Nortier JW, Kroep JR (2011) Discordances in ER, PR and HER2 receptors after neoadjuvant chemotherapy in breast cancer. Cancer Treat Rev 37(6):422-430. https://doi.org/10.1016/j.ctrv.2010.11.006

20. Wang RX, Chen S, Jin X, Chen CM, Shao ZM (2017) Weekly paclitaxel plus carboplatin with or without trastuzumab as neoadjuvant chemotherapy for HER2-positive breast cancer: loss of HER2 amplification and its impact on response and prognosis. Breast Cancer Res Treat 161(2):259-267. https://doi.org/10.1007/ s10549-016-4064-9

21. Guarneri V, Dieci MV, Barbieri E, Piacentini F, Omarini C, Ficarra G, Bettelli S, Conte PF (2013) Loss of HER2 positivity and prognosis after neoadjuvant therapy in HER2-positive breast cancer patients. Ann Oncol 24(12):2990-2994. https://doi. org/10.1093/annonc/mdt364

22. Goldhirsch A, Winer EP, Coates AS, Gelber RD, Piccart-Gebhart M, Thurlimann B, Senn HJ, Panel m (2013) Personalizing the treatment of women with early breast cancer: highlights of the St Gallen International Expert Consensus on the primary therapy of early breast cancer 2013. Ann Oncol 24(9):2206-2223. https:// doi.org/10.1093/annonc/mdt303

23. Prat A, Cheang MC, Martin M, Parker JS, Carrasco E, Caballero R, Tyldesley S, Gelmon K, Bernard PS, Nielsen TO, Perou CM (2013) Prognostic significance of progesterone receptorpositive tumor cells within immunohistochemically defined luminal A breast cancer. J Clin Oncol 31(2):203-209. https://doi. org/10.1200/jco.2012.43.4134

24. Bruening W, Fontanarosa J, Tipton K, Treadwell JR, Launders J, Schoelles K (2010) Systematic review: comparative effectiveness of core-needle and open surgical biopsy to diagnose breast lesions. Ann Intern Med 152(4):238-246. https://doi.org/10.7326/00034819-152-1-201001050-00190

25. Pijnappel RM, van Dalen A, Borel Rinkes IH, van den Tweel JG, Mali WP (1997) The diagnostic accuracy of core biopsy in palpable and non-palpable breast lesions. Eur J Radiol 24(2):120-123

26. Lebeau A, Turzynski A, Braun S, Behrhof W, Fleige B, Schmitt WD, Grob TJ, Burkhardt L, Holzel D, Jackisch C, Thomssen C, Muller V, Untch M (2010) Reliability of human epidermal growth factor receptor 2 immunohistochemistry in breast core needle biopsies. J Clin Oncol 28(20):3264-3270. https://doi.org/10.1200/ jco.2009.25.9366

27. Arnedos M, Nerurkar A, Osin P, A'Hern R, Smith IE, Dowsett M (2009) Discordance between core needle biopsy (CNB) and excisional biopsy (EB) for estrogen receptor (ER), progesterone receptor $(\mathrm{PgR})$ and HER2 status in early breast cancer (EBC). Ann
Oncol 20(12):1948-1952. https://doi.org/10.1093/annonc/mdp23

28. Lorgis V, Algros MP, Villanueva C, Chaigneau L, Thierry-Vuillemin A, Nguyen T, Demarchi M, Bazan F, Sautiere JL, Maisonnette-Lescot Y, Ringenbach F, Bontemps P, Pivot X (2011) Discordance in early breast cancer for tumour grade, estrogen receptor, progesteron receptors and human epidermal receptor-2 status between core needle biopsy and surgical excisional primary tumour. Breast 20(3):284-287. https://doi.org/10.1016/j.breas t.2010.12.007

29. Chen X, Yuan Y, Gu Z, Shen K (2012) Accuracy of estrogen receptor, progesterone receptor, and HER2 status between core needle and open excision biopsy in breast cancer: a meta-analysis. Breast Cancer Res Treat 134(3):957-967. https://doi.org/10.1007/ s10549-012-1990-z

30. Meattini I, Bicchierai G, Saieva C, De Benedetto D, Desideri I, Becherini C, Abdulcadir D, Vanzi E, Boeri C, Gabbrielli S, Lucci F, Sanchez L, Casella D, Bernini M, Orzalesi L, Vezzosi V, Greto D, Mangoni M, Bianchi S, Livi L, Nori J (2017) Impact of molecular subtypes classification concordance between preoperative core needle biopsy and surgical specimen on early breast cancer management: single-institution experience and review of published literature. Eur J Surg Oncol 43(4):642-648. https://doi. org/10.1016/j.ejso.2016.10.025

31. Chen X, Sun L, Mao Y, Zhu S, Wu J, Huang O, Li Y, Chen W, Wang J, Yuan Y, Fei X, Jin X, Shen K (2013) Preoperative core needle biopsy is accurate in determining molecular subtypes in invasive breast cancer. BMC Cancer 13:390. https://doi. org/10.1186/1471-2407-13-390

32. Polley MY, Leung SC, McShane LM, Gao D, Hugh JC, Mastropasqua MG, Viale G, Zabaglo LA, Penault-Llorca F, Bartlett JM, Gown AM, Symmans WF, Piper T, Mehl E, Enos RA, Hayes DF, Dowsett M, Nielsen TO (2013) An international Ki67 reproducibility study. J Natl Cancer Inst 105(24):1897-1906. https:// doi.org/10.1093/jnci/djt306

33. Dowsett M, Nielsen TO, A'Hern R, Bartlett J, Coombes RC, Cuzick J, Ellis M, Henry NL, Hugh JC, Lively T, McShane L, Paik S, Penault-Llorca F, Prudkin L, Regan M, Salter J, Sotiriou C, Smith IE, Viale G, Zujewski JA, Hayes DF, International Ki-67 in Breast Cancer Working G (2011) Assessment of Ki67 in breast cancer: recommendations from the International $\mathrm{Ki} 67$ in breast cancer working group. J Natl Cancer Inst 103(22):1656-1664. https:// doi.org/10.1093/jnci/djr393

34. You K, Park S, Ryu JM, Kim I, Lee SK, Yu J, Kim SW, Nam SJ, Lee JE (2017) Comparison of core needle biopsy and surgical specimens in determining intrinsic biological subtypes of breast cancer with immunohistochemistry. J Breast Cancer 20(3):297303. https://doi.org/10.4048/jbc.2017.20.3.297

35. Dekker TJ, Smit VT, Hooijer GK, Van de Vijver MJ, Mesker WE, Tollenaar RA, Nortier JW, Kroep JR (2013) Reliability of core needle biopsy for determining ER and HER2 status in breast cancer. Ann Oncol 24(4):931-937. https://doi.org/10.1093/annon c/mds599

36. Hammond ME, Hayes DF, Dowsett M, Allred DC, Hagerty KL, Badve S, Fitzgibbons PL, Francis G, Goldstein NS, Hayes M, Hicks DG, Lester S, Love R, Mangu PB, McShane L, Miller K, Osborne CK, Paik S, Perlmutter J, Rhodes A, Sasano H, Schwartz JN, Sweep FC, Taube S, Torlakovic EE, Valenstein P, Viale G, Visscher D, Wheeler T, Williams RB, Wittliff JL, Wolff AC (2010) American Society of Clinical Oncology/College Of American Pathologists guideline recommendations for immunohistochemical testing of estrogen and progesterone receptors in breast cancer. J Clin Oncol 28(16):2784-2795. https://doi.org/10.1200/ JCO.2009.25.6529

37. Wolff AC, Hammond ME, Schwartz JN, Hagerty KL, Allred DC, Cote RJ, Dowsett M, Fitzgibbons PL, Hanna WM, Langer 
A, McShane LM, Paik S, Pegram MD, Perez EA, Press MF, Rhodes A, Sturgeon C, Taube SE, Tubbs R, Vance GH, van de Vijver M, Wheeler TM, Hayes DF (2007) American Society of Clinical Oncology/College of American Pathologists guideline recommendations for human epidermal growth factor receptor 2 testing in breast cancer. J Clin Oncol 25(1):118-145. https://doi. org/10.1200/jco.2006.09.2775

38. Polyak K (2011) Heterogeneity in breast cancer. J Clin Invest 121(10):3786-3788. https://doi.org/10.1172/jci60534

39. Marusyk A, Almendro V, Polyak K (2012) Intra-tumour heterogeneity: a looking glass for cancer? Nat Rev Cancer 12(5):323-334. https://doi.org/10.1038/nrc3261

40. Martelotto LG, Ng CK, Piscuoglio S, Weigelt B, Reis-Filho JS (2014) Breast cancer intra-tumor heterogeneity. Breast Cancer Res 16(3):210. https://doi.org/10.1186/bcr3658

41. Karthik GM, Rantalainen M, Stalhammar G, Lovrot J, Ullah I, Alkodsi A, Ma R, Wedlund L, Lindberg J, Frisell J, Bergh J, Hartman J (2017) Intra-tumor heterogeneity in breast cancer has limited impact on transcriptomic-based molecular profiling. BMC Cancer 17(1):802. https://doi.org/10.1186/s12885-017-3815-2

42. Robertson S, Stalhammar G, Darai-Ramqvist E, Rantalainen M, Tobin NP, Bergh J, Hartman J (2018) Prognostic value of Ki67 analysed by cytology or histology in primary breast cancer. J Clin Pathol 71(9):787-794. https://doi.org/10.1136/jclinpath-2017204976
43. Stalhammar G, Rosin G, Fredriksson I, Bergh J, Hartman J (2014) Low concordance of biomarkers in histopathological and cytological material from breast cancer. Histopathology 64(7):971-980. https://doi.org/10.1111/his.12344

44. Lindstrom LS, Karlsson E, Wilking UM, Johansson U, Hartman J, Lidbrink EK, Hatschek T, Skoog L, Bergh J (2012) Clinically used breast cancer markers such as estrogen receptor, progesterone receptor, and human epidermal growth factor receptor 2 are unstable throughout tumor progression. J Clin Oncol 30(21):26012608. https://doi.org/10.1200/jco.2011.37.2482

45. Cejalvo JM, Martinez de Duenas E, Galvan P, Garcia-Recio S, Gasion OB, Pare L, Antolin S, Martinello R, Blancas I, Adamo B, Guerrero-Zotano A, Munoz M, Nuciforo P, Vidal M, Perez RM, Chacon Lopez-Muniz JI, Caballero R, Peg V, Carrasco E, Rojo F, Perou CM, Cortes J, Adamo V, Albanell J, Gomis RR, Lluch A, Prat A (2017) Intrinsic subtypes and gene expression profiles in primary and metastatic breast cancer. Cancer Res 77(9):22132221. https://doi.org/10.1158/0008-5472.Can-16-2717

46. Lee JY, Park K, Lee E, Ahn T, Jung HH, Lim SH, Hong M, Do IG, Cho EY, Kim DH, Kim JY, Ahn JS, Im YH, Park YH (2016) Gene expression profiling of breast cancer brain metastasis. Sci Rep 6:28623. https://doi.org/10.1038/srep28623 